\title{
Paradigmas, eixos temáticos e tensões na PTO no Brasil
}

\author{
Pedro F. Bendassolli \\ Universidade Federal do Rio Grande do Norte \\ Jairo Eduardo Borges-Andrade \\ Universidade de Brasília \\ Sigmar Malvezzi \\ Universidade de São Paulo
}

\begin{abstract}
Resumo
O panorama de abordagens da psicologia do trabalho e das organizações (PTO) no Brasil mostra grande diversidade teórica e metodológica que reflete a presença de distintos paradigmas científicos na delimitação e organização desse campo. O objetivo deste artigo é analisar esses paradigmas e relacioná-los com três eixos temáticos da PTO no Brasil: o do comportamento, o da subjetividade e o clínico. Investiga-se os fundamentos epistemológicos e metodológicos, alguns trabalhos e autores de cada um desses eixos, discutindo sua contribuição para o campo da PTO no Brasil. O artigo desenvolve uma discussão sobre as tensões existentes entre esses eixos, derivadas da pressão de corresponderem, ao mesmo tempo, a critérios de rigor acadêmico e relevância organizacional. O artigo, por fim, mostra a diversificação do campo da PTO no Brasil e os desafios disso decorrentes.
\end{abstract}

Palavras-chave: Psicologia do trabalho; psicologia das organizações; paradigmas científicos; metodologia de pesquisa; filosofia da ciência.

\begin{abstract}
Work and organizational psychology paradigms, thematic streams and tensions in Brazil. The great theoretical and methodological diversity of Work and Organizational Psychology (WOP) approaches in Brazil reflects the presence of distinct scientific paradigms in the setting of boundaries and the organization of this field. The purpose of this paper is to analyze these paradigms and relate them with three WOP thematic streams in Brazil: the behavioral stream; the subjectivity stream; and the clinical stream. We investigate epistemological and methodological fundamentals, some studies and authors in each of these streams, discussing their contribution to the field of WOP in Brazil. The paper discusses the stresses that exist among these streams, which arise from the pressure of corresponding at once to academic rigor and organizational relevance criteria. Finally, the article shows the diversification of the field of WOP in Brazil and resulting challenges.

Keywords: Work psychology; organizational psychology; scientific paradigms; research methodology; philosophy of science.
\end{abstract}

$\mathrm{O}$ psicólogo do trabalho e das organizações (PTO) brasileiro já foi alvo de diversas radiografias destinadas a escrutinar sua atuação profissional (Bastos \& Gondim, 2010; Bastos \& Martins, 1989; Borges-Andrade, 1990; Zanelli, 2002; Zanelli \& Bastos, 2004). Focalizadas em aspectos da profissão-em-uso, essas radiografias mostram a diversidade de campos de trabalho, as dimensões demográficas da profissão, as fases históricas de seu desenvolvimento, as dificuldades enfrentadas, os desafios, as tendências e as avaliações feitas pelo profissional PTO. Número menor de estudos foi dedicado à análise da filiação paradigmática. Este artigo tem por finalidade contribuir para a análise crítica do conhecimento produzido e utilizado por esse profissional, confrontando os paradigmas e os eixos que aglutinam sua atuação. Serão analisados três temas-chaves como recorte circunscrito da heterogeneidade de eixos que compõem a área da PTO no Brasil na atualidade: comportamento, subjetividade e clínica. Embora diferenciados entre si nas distintas inscrições paradigmáticas, direta ou indiretamente, o elemento integrador desses eixos é o trabalho.

$O$ conceito de paradigma ganhou espaço por meio do ensaio de Kuhn (1962) sobre as bases e modelos da ciência. O termo foi amplamente popularizado, tornando-se até vítima de usos abusivos, como reificações e aplicações feitas sem o cuidado de demarcação semântica. A expressão "quebra de paradigma" tornou-se um jargão popular na área de recursos humanos como metáfora de mudança organizacional e, frequentemente, vazio de sentido. O conceito de paradigma é aqui proposto como meio para a análise de plataformas teóricas, metodológicas e práticas no campo da PTO.

O artigo está organizado em três partes. A primeira é dedicada à apresentação dos traços de paradigmas influentes na concepção de ciência herdada do século passado. Na segunda, 
constrói-se uma descrição dos três eixos temáticos a partir de uma grade de análise. Finalmente, esses eixos são comparados entre si e são apontadas tensões que emergem de sua coexistência na pesquisa e intervenção feitas em PTO.

\section{Paradigmas como categorias de análise}

\section{Do monismo à pluralidade}

Usado pela primeira vez no século dezenove por Augusto Comte, o positivismo ganhou popularidade e apoio como sólida base lógica para o conhecimento científico, capaz de se ajustar (como neo-positivismo) à dinâmica da sociedade da primeira metade do século vinte. Kolakowski (1972) identifica quatro principais postulados do positivismo: primeiro, que o conhecimento refere-se exclusivamente àquilo que pode ser apreendido por meio da experiência sensorial; segundo, que a ciência deve se interessar apenas por objetos concretos (e não por elementos abstratos); terceiro, que há diferenças importantes entre julgamentos de valor e julgamento de fatos; e que as ciências naturais, em particular a física, são o modelo de ciência a ser imitado. A tradição de investigação experimental é associada a esses postulados. Tais postulados encontraram resistências dentro da filosofia no início do século vinte. Dilthey (1911/1992) opôs-se frontalmente ao postulado da unidade da ciência, defendendo a separação entre ciências do espírito (nas quais ele alocou a psicologia) e as ciências da natureza, cada uma delas demandando um objeto próprio de investigação. $\mathrm{O}$ debate entre explicação e compreensão, que atravessou a história da filosofia da ciência até os dias atuais, tem aí uma de suas origens, assim como a distinção (metodológica) proposta por Wilhelm Windelband, no final do século dezenove (Weber, 1922/2001), entre ciências nomotéticas, orientadas pela elaboração de leis gerais, e ciências idiográficas, orientadas pelo estudo da particularidade de certos fenômenos. Esses debates abrigaram as primeiras distinções entre métodos quantitativos e qualitativos, respectivamente.

Nos anos 1930, o positivismo foi reforçado com o aparecimento de sua variante lógica proposta pelos filósofos do Círculo de Viena (Ayer, 1959). Conforme destaca Weinberg (1936), dois propósitos centrais guiaram esse grupo: prover uma fundação sólida para a ciência e mostrar a falta de sentido de qualquer empreendimento metafísico. O principal suporte para o ataque feito à metafísica foi a lógica - obtida de filósofos como Wittgenstein, Frege e Russel. Para os positivistas lógicos, só dois tipos de enunciados seriam científicos: os analíticos, derivados da aplicação da lógica formal de ciências formais (como a matemática), e os observacionais, pertencentes às ciências empíricas. Estes ainda dependiam da confirmação advinda de sua submissão à exigência da verificabilidade.

Embora desfeito pelo nazismo, o Círculo de Viena manteve sua influência através do que veio a ser conhecido como concepção herdada (Echeverría, 1989). Nesta, a principal novidade foi a distinção entre contexto de descobrimento e contexto de justificação. O primeiro diz respeito ao modo como se chega aos resultados científicos, e o segundo se refere ao modo como esses resultados são expostos e justificados. Essa diferença destacou a exigência da disjunção entre interesses, valores e circunstâncias do pesquisador e da pesquisa (contexto de descobrimento) para se criar as condições de objetividade, verdade e da construção racional do conhecimento científico (contexto de justificação). A concepção herdada, ou neopositivismo, reforçou a importância do método hipotético-dedutivo e do verificacionismo, insistindo para que se entendessem os termos teóricos como constructos que poderiam predizer acontecimentos do mundo fenomênico.

Uma onda de questionamentos começou a se intensificar contra as concepções neopositivistas, notadamente partindo da sociologia do conhecimento de Mannheim (1936). Este critica a ideia positivista de que o conhecimento é construído como se houvesse um mundo exterior ao qual o pesquisador tem acesso via métodos objetivos - métodos esses que o protegeriam da influência de seus próprios valores, crenças, expectativas e interesses. Mannheim destaca que não há possibilidade de tal acesso e que a objetividade não existe senão em função dos grupos sociais que constroem conhecimentos específicos sobre a realidade. Propõe um processo social de construção do conhecimento que traz, para o primeiro plano, questões do contexto de descobrimento.

As críticas ao positivismo continuaram de Mannheim para toda a sociologia. A Escola de Chicago (Chapoulie, 2001), berço do interacionismo simbólico nos EUA, ficou conhecida por seu questionamento do método experimental. Criticavamse as simulações de problemas concretos desconectadas de seus contextos reais e a separação sujeito-objeto, propondose a interação reflexiva entre estes. Correntes "qualitativas" surgiram dos anos de 1930 aos 1960 influenciando a psicologia, como constatado no interacionismo simbólico (Mead, 1934), na etnometodologia (Garfinkel, 1967), e também na sociologia fenomenológica (Schutz, 1962). Enriquecida com esse debate, a psicologia aparece nos anos 1960 caracterizada pelo pluralismo metodológico.

\section{O conceito de paradigma}

É no contexto desse pluralismo e da crise do positivismo nos anos de 1960 que floresce o conceito de paradigma. Na década de 1970 as transformações na filosofia da ciência foram ainda mais profundas com o avanço da proposta de Kuhn (1962) e com os trabalhos de Imre Lakatos e Paul Feyerabend. Kuhn questionou as bases racionais da ciência contidas no positivismo herdado e deslocou o foco do contexto de justificação para o de descoberta, destacando a importância de os pesquisadores compreenderem os determinantes históricos e sociais da ciência.

Paradigma pode ser traduzido como um conjunto de premissas coerentes entre si que orientam a busca do conhecimento científico. Como tal, ele tem função cognitiva ao permitir o compartilhamento de certos esquemas mentais dentro de um mesmo grupo da comunidade científica, e uma função política ao sedimentar abordagens e ao justificar posicionamentos e arranjos de poder.

Um paradigma é também uma meta-teoria, constituída por pilares ontológico, epistemológico e metodológico (Guba, 1990). Do ponto de vista ontológico, todo paradigma busca responder à questão: Qual a natureza daquilo que é conhecível? Epistemologicamente, a questão é: Qual a natureza do relacionamento entre aquele que conhece (o 
pesquisador) e o objeto a ser conhecido (ou conhecível)? Por fim, metodologicamente, a questão é: Como o pesquisador deve proceder para alcançar aquilo que é conhecível?

\section{Tipologia de paradigmas}

Apresentamos e discutimos nesta seção quatro paradigmas e suas respectivas composições nos termos das categorias propostas por Guba (1990). O paradigma positivista assentase em postulados que enfatizam a importância da fundação empírica para o conhecimento e da postura neutra e distanciada do pesquisador diante do objeto de estudo. Guba (1990) destaca que esses postulados enraízam-se na ontologia realista, na crença de que existe uma realidade externa dirigida por leis naturais imutáveis. A função da ciência é descobrir a verdadeira natureza da realidade. Seu objetivo último é predizer e controlar. Como consequência do compromisso com o realismo ontológico, a prática de pesquisa positivista é condicionada pela epistemologia objetivista. Daí, segundo Guba, o privilégio dado ao método experimental, uma vez que este coloca o ponto de decisão na natureza (objetividade), e não no pesquisador (subjetividade).

O paradigma pós-positivista é uma versão modificada do anterior. Guba (1990) menciona que seu aparecimento decorreu da tentativa de salvar o positivismo das críticas que sofreu. Ontologicamente, o pós-positivismo afasta-se da postura realista ingênua, que acredita na possibilidade de acesso direto à realidade em si. Mesmo preservando a ideia da existência do mundo objetivo dirigido por leis naturais, aceita-se que é impossível para os seres humanos verdadeiramente perceber e acessar a realidade com seus mecanismos sensoriais e intelectuais imperfeitos. Da mesma forma, o pós-positivismo migrou para a epistemologia objetivista do tipo crítico, no exato sentido de tomar a objetividade como ideal regulatório. Admite-se que só aproximadamente é possível alcançar a objetividade, e nesse processo são decisivas tanto a tradição de um dado ramo de conhecimento quanto da comunidade científica. Produziu-se uma modificação no experimentalismo ao se incluir nele metodologias múltiplas, hoje conhecidas como triangulação (Denzin, 1970).

O paradigma crítico introduz maior distanciamento em relação aos dois anteriores. O termo crítico certamente não é o mais adequado, não só porque é amplo em demasia como também porque dizer que este é um paradigma crítico não significa que os outros não o sejam. Mesmo com essa imperfeição terminológica, Guba (1990) e Montero (1996) sugerem sua adoção a título alusivo. Guba menciona que um elemento convergente nas várias abordagens influenciadas por esse paradigma é a rejeição do postulado positivista da isenção de valores. Para o paradigma crítico, as teorias científicas refletem os valores de seus proponentes; não são neutras, e a presença de valores não é um viés da investigação, mas sua condição mesma. Com isso, a pesquisa torna-se um ato político, baseada na ontologia realista crítica, mas, contrariamente aos dois paradigmas anteriores, defende-se neste uma epistemologia subjetivista, no preciso sentido de que os valores são moderadores da investigação. A realidade torna-se objeto do conhecimento com o intuito de enriquecer a consciência para sua transformação. Por essa razão, a metodologia é dialética, pois visa levar os participantes a se confrontarem com sua falsa consciência para então superá-la.
O paradigma clínico consiste no estudo da pessoa como uma totalidade considerada na relação com sua história e seu contexto. Uma ilustração típica desse paradigma é encontrada na psicanálise. Contudo, é necessário lembrar que a psicanálise não é um conjunto homogêneo de idéias, escolas, abordagens, como se conhece das diversas tentativas de situá-la no debate paradigmático (Mezan, 2007). A despeito dessas dificuldades, a psicanálise tem sido um paradigma influente (Mettens, 2006), útil (Dejours, 1993) e em constante crescimento na PTO, desde o trabalho de Menzies (1970) e passando pela pesquisa seminal de Pagés, Bonetti, Gaulejac e Descendre (1986). Mantendo a estrutura de comparação descrita por Guba (1990), pode-se assumir que a psicanálise compartilha, em termos gerais, da ontologia realista crítica. Quer dizer, de um lado admite-se a realidade, neste caso, psíquica, mas de outro ela é questionada, desconstruída, no processo de análise para expor conteúdos inconscientes latentes. Epistemologicamente, a psicanálise, especialmente a freudiana, instiga a reflexão sobre a postura intersubjetiva, na qual dois sujeitos são colocados na cena e, mediante o recurso da interpretação, um deles devolve aos outros aspectos importantes da dinâmica inconsciente aí apurados.

\section{Eixos temáticos da PTO e paradigmas}

Com a discussão anterior em mente, a tarefa seguinte deste artigo é analisar a relação entre os eixos comportamento, subjetividade e clínico e os quatro paradigmas recém-descritos.

\section{Eixo do comportamento}

O eixo do comportamento está associado ao behaviorismo, ao neobehaviorismo e ao sociocognitivismo. No primeiro caso, comportamento é sinônimo de ação realizada dentro e por força do ambiente, e de cuja observação é possível extrair suas causas e consequências. No caso do neobehaviorismo, tal como na transição para o neopositivismo, ocorre a revisão de premissas básicas e a inserção de uma dimensão mediadora entre o estímulo recebido do meio e o comportamento do indivíduo. Hull (1943), ao propor seu modelo de aprendizagem, plantou a primeira semente para a transição da visão do comportamento como ação observável para estudos que consideravam suas dimensões cognitivas. Consistente com ele, Bandura, com sua proposta de mediação, também foi decisivo nessa consideração (Bandura \& Mischel, 1965). A partir de então, o modelo de compreensão do comportamento torna-se mais engenhoso, passando a incorporar dimensões cognitivas e afetivas como mediadoras entre o contexto do indivíduo e seu comportamento.

Essa tendência se intensificaria mais ainda com o sociocognitivismo, uma linha que emerge junto da virada cognitivista na psicologia no final dos anos de 1950, e cujos precedentes já haviam sido estabelecidos por Bartlett (1932), o qual propõe a ruptura com a tradição behaviorista ao enfatizar a importância dos esquemas cognitivos e sua origem sociocultural, e, em outra tradição, por Vygostki (1934/1991), o qual põe ênfase na consciência como fenômeno sociohistórico mediado simbolicamente e defende o caráter interpretativo da psicologia. Nesta tendência não se poderia omitir a contribuição da Gestalt para o desenvolvimento de nova compreensão do comportamento, visto como produto do ambiente e do processo 
de atribuição de significados pelo indivíduo.

Após a virada cognitiva, o sociocognitivismo se viu impulsionado pela forte presença do modelo de processamento de informação proposto durante os anos de 1960 (Miller, Galanter, \& Pribam, 1960), pelos estudos dos esquemas e estruturas cognitivas (Bruner, Goodnow, \& Austin, 1956) e pela teoria de aprendizagem social (Bandura, 1977). O campo da PTO, especialmente nos EUA, sob diversas influências como as pesquisas da psicologia diferencial (seleção, testes de inteligência e aptidão, etc.), com seu enraizamento na filosofia pragmatista norte-americana e na psicologia aplicada (Koppes \& Pickren, 2007), diversifica as investigações sobre processos cognitivos em grupos (influência social, liderança, equipes etc.), a motivação no trabalho, o desenvolvimento (aprendizagem) profissional, os processos de tomada de decisão e as atitudes, entre muitos outros.

No Brasil, esse eixo de investigações representa importante faceta do campo. A coletânea recentemente organizada por Siqueira (2008) permite observar esse direcionamento, com autores vinculados a diversas instituições de pesquisa brasileiras. Nela são apresentadas medidas padronizadas para diversos constructos da PTO, tais como poder, cultura, clima e comprometimento organizacional, justiça e equipes no trabalho, motivação e valores, precedidas de revisão de literatura, definições operacionais de constructos e relatos de coleta, análise e interpretação de dados. Este eixo também está bem representado na obra publicada por Borges-Andrade, Abbad e Mourão (2006). Há certa convergência nos métodos, especificamente no uso da estatística, com inspiração predominantemente correlacional, visando o diagnóstico e a gestão.

É importante que se diga que a inspiração propriamente experimental, com desenhos de pesquisa com forte acento no controle de variáveis, perdeu força no Brasil em decorrência, em um plano mais concreto, da falta de recursos e, num plano mais amplo, da pressão exercida pelos outros eixos e paradigmas aqui comentados, bem como dos praticantes, profissionais atuando cotidianamente nas organizações de trabalho e com demandas de pesquisa para elaboração de intervenções/aplicações nos processos práticos de gestão. No cenário internacional, a situação parece mais diversificada, coexistindo experimentos de laboratório e outras modalidades de pesquisa nas quais se observa maior proximidade com as problemáticas dos praticantes (Anderson, Herriot, \& Hodgkinson, 2001).

Este eixo parece ser hoje melhor representado, no país, pelos desenhos correlacionais e pelas pesquisas de campo (surveys), nos quais se exige a operacionalização de constructos, mensuração e controle de variáveis. Trabalha-se com o pressuposto da variabilidade das medidas e da probabilidade de ocorrência dos fenômenos que buscam predizer. A diferença em relação ao método experimental é que o correlacional não adere a um programa de causalidade "pesada" - ao menos não a unicausalidade. Em vez disso, parte-se do princípio da multicausalidade ou multideterminação dos fenômenos, abrindo margem para a evolução das pesquisas orientadas por métodos multiníveis (Klein \& Kozlowski, 2000).

\section{Eixo da subjetividade}

A investigação da subjetividade foi intensificada no
Brasil, nas duas últimas décadas, fato observado no simples levantamento das linhas de pesquisa dos diversos programas de pós-graduação em psicologia no país. Neles é frequente o interesse pela ligação entre subjetividade e trabalho. Para citar não mais do que alguns poucos exemplos, no programa da Universidade Estadual do Rio de Janeiro, estuda-se os processos de subjetivação no trabalho; na Universidade Federal do Rio de Janeiro, subjetividade é associada às práticas culturais e clínicas, também incluindo o trabalho; na Pontifícia Universidade Católica de São Paulo há um núcleo de subjetividade, em que também são conduzidos estudos sobre suas relações com o trabalho. Há por fim referências a linhas de pesquisa em subjetividade e trabalho em diversas outras instituições federais de ensino - o que podemos observar por diversas publicações, tais como as citadas ao final desta seção.

Definir o conceito de subjetividade neste eixo não é tarefa fácil, especialmente porque ele é encontrado em diversas abordagens fora e dentro da psicologia e também porque o primeiro eixo, já citado aqui, também dele se apropriou, quando incorporou cognições e afetos como mediadores entre o contexto do indivíduo e o seu comportamento. O mesmo vale para o próximo eixo, o clínico, que também se apropriou do conceito de subjetividade. Contudo, e a despeito do risco, há indícios de traços comuns nas abordagens presentes neste eixo.

Subjetividade, no caso deste segundo eixo, refere-se ao sujeito. Este é quem conhece, assim como é o fundamento do próprio conhecimento. Na história da filosofia moderna, atribuise a Descartes e a Kant a virada em favor da subjetividade (Benoist, 1995). Em Descartes, o sujeito é o cogito, o ser pensante que cognitivamente representa o mundo no espaço interno da mente (Rorty, 1979). Em Kant, novamente é o sujeito a base (nesse caso, lógica) do conhecimento, o que enuncia o discurso, mas é também o sujeito moral, o que tem o dever como princípio ético, responsável por suas próprias ações.

Outro elemento a ser constatado no conceito de subjetividade é o modo como o sujeito é, ele próprio, construído graças à ação de determinadas forças sociohistóricas. Este segundo elemento é encontrado nas abordagens ditas pós-estruturalistas, mais notadamente na obra de filósofos como Michel Foucault e Gilles Deleuze. Foucault exerceu influência inquestionável em certas correntes da psicologia brasileira. No início de sua obra, a subjetividade é entendida como um efeito de certos poderes e saberes, de epistemes e disciplinas (Foucault, 1984a, 1986, 1987). Ali o sujeito é apreendido no sentido de assujeitado, de determinado de fora, e não como uma instância autônoma e racional.

Em outro momento de sua obra, Foucault (1984b, 1984c) alterna sua compreensão do sujeito e da subjetividade, passando a ver esta última como um processo social e histórico pelo qual o sujeito constrói determinadas formas de relação consigo mesmo - a ética de si. Este caráter processual, histórico, faz a terminologia incluir o conceito de processos de subjetivação, bastante explorados nesse eixo temático. Tais processos pretendem chamar a atenção para o caráter construído da realidade e para a dimensão relativista das verdades aceitas como inquestionáveis, especialmente sobre o sujeito. Daí a metodologia adotada ser genealógica, pois se parte das coisas 
como elas são para reconstituir sua origem e evolução.

No campo da PTO, os estudos partindo do referencial pósestruturalista sobre subjetividade e processos de subjetivação dedicam-se à exploração de amplo leque de temas, cuja síntese seria impossível de apresentar integralmente aqui. Contudo, além do que já foi dito, é possível pontuar alguns tópicos comuns de investigação, tais como a crítica a processos tradicionais de institucionalização do trabalho; a tentativa de empoderar indivíduos e grupos sociais em condições de fragilização no trabalho; a genealogia de formas de construção e disseminação de significados sobre o trabalho; o desenvolvimento de políticas públicas que levem em conta fatores subjetivos; o estudo dos impactos subjetivos do desemprego, subemprego e de processos de reestruturação produtiva; a relação entre trabalho e questões de gênero. Alguns exemplos brasileiros de estudos sobre subjetividade e trabalho podem ser encontrados em Barros (2009), Brito, Athayde e Alvarez (2004), Carreteiro e Barros (2010), Davel e Vergara (2001), Freitas (2005), Mello (2007), Nardi (2006), Ramminger e Nardi (2008), Vasconcelos e Davel (2000), Vieira e Goulart (2007), e Tittoni e Nardi (2006).

Entre as contribuições deste eixo para a PTO brasileira, destacamos a diversificação que ele promove em nossas concepções de sujeito, sendo uma resposta imediata à tradição positivista que via o sujeito como um agente autônomo regulado por cognições e estímulos do ambiente. Na perspectiva da subjetividade, o sujeito é uma produção ao mesmo tempo social e psicológica. Como resultado, os autores deste eixo recorrem a métodos e técnicas que possibilitem a análise de amplos conjuntos de significados sobre o sujeito, seu contexto, e sobre a participação do trabalho nos processos de subjetivação. Entre as diversas técnicas utilizadas, podemos citar a entrevista compreensiva, a análise de discursos e narrativas, as histórias de vida e também certos recursos desenvolvidos no campo da análise institucional. Com forte influência do paradigma crítico, as pesquisas conduzidas neste eixo buscam subsidiar processos de intervenção e transformação das condições de trabalho, especialmente do ponto de vista do trabalhador e dos coletivos de trabalho.

\section{Eixo clínico}

Recentemente, foi proposto o termo clínicas do trabalho (Bendassolli \& Soboll, 2010; Lhuilier, 2006) para caracterizar abordagens que, mesmo sem focar a questão psicoterapêutica, partilham características do paradigma clínico, tais como o foco em metodologia qualitativa, o recurso à interpretação, a ênfase na profundidade da compreensão de casos específicos em detrimento de descrições ou descobertas de leis gerais. Essa perspectiva se considera emancipadora, pois visa ao empoderamento do trabalhador, seja em situações de sofrimento ou vulnerabilidade, como também diante de bloqueios ou suspensões de seu poder de agir (Clot, 2008). Há, como no eixo anterior, o propósito de recuperar a discussão sobre subjetividade no contexto de trabalho. Neste caso, porém, subjetividade parece portar o sentido adicional de resistência (Martuccelli, 2002), crítica, espaço no qual se busca preservar ou defender dimensões importantes do sujeito psíquico - muitas delas esquecidas pelas organizações capitalistas (Chanlat, 1990).
Quatro grandes abordagens podem ser identificadas neste eixo: a ergologia, a psicodinâmica do trabalho, a sociologia clínica (ou psicossociologia) e a clínica da atividade. A análise da psicodinâmica do trabalho proposta por Dejours (1993, 1994, 1999), abordagem popularizada no Brasil, será aqui, por razões de espaço, tomada como amostra das outras três abordagens deste eixo.

Em linhas gerais, na psicodinâmica, cuja história de desenvolvimento marca o deslocamento da tradição da psicopatologia do trabalho francesa em direção à psicanálise freudiana e a outras matrizes compreensivas, o trabalho é considerado dimensão-chave do processo de estruturação psíquica do sujeito (Dejours, 1994, 1999). A análise do trabalho é feita pelos instrumentais da tradição ergológica francesa, especificamente sua distinção entre trabalho prescrito (planejado) e trabalho real (o que de fato se passa com o trabalhador em sua relação com a tarefa). A leitura do hiato entre ambas é feita pelo recurso à psicanálise, donde a ideia de que o tamanho desse hiato pode implicar sofrimento psíquico, como também pode implicar confronto positivo do sujeito, o qual, assim, consegue firmar seu desejo contra a realidade laboral. Na psicodinâmica, um dos principais objetivos do pesquisador é a compreensão das condições do trabalho (tanto sua divisão como organização), tendo em vista a emancipação do trabalhador do sofrimento.

No contexto local, uma obra recentemente organizada por Mendes (2008) fornece uma amostra dos interesses e dos tópicos de pesquisa e intervenção da psicodinâmica, como por exemplo, a questão do tempo no trabalho, do prazer ligado ao reconhecimento, elementos de ergonomia, processos de subjetivação no capitalismo flexível, centralidade do trabalho, sofrimento e saúde mental. Do ponto de vista metodológico, observa-se a priorização da dimensão qualitativa, materializada em estudos de caso e na prática das entrevistas. Entre a diversidade de outras pesquisas conduzidas dentro deste eixo, destacamos Lancman e Heloani (2004), Lancman e Uchida (2003), Macêdo (1999, 2010), Mendes, Merlo, Morrone e Facas (2010), Merlo (2002). As contribuições deste eixo para o campo da PTO no Brasil ocorrem em diversos níveis. Primeiramente, no da pesquisa, com a introdução de novos métodos e técnicas de investigação e intervenção. Por exemplo, no caso da psicodinâmica, há a introdução de uma perspectiva clínica fundamentada nos pressupostos da psicanálise, mas também no da ergonomia e da sociologia. No caso da clínica da atividade, seus autores desenvolveram as técnicas da "auto-confrontação cruzada" e da "instrução ao sósia", ambas como alternativas às técnicas quantitativas de coleta de dados sobre os contextos de trabalho (Clot, 2008; Osório da Silva, Barros de Barros, \& Louzada, 2010). O mesmo se observa na ergologia, notadamente com a proposição do "dispositivo dinâmico de três polos" (Athayde \& Brito, 2010).

Em segundo lugar, todos os autores que se filiam às clínicas do trabalho compartilham de pressupostos ontológicos e epistemológicos que apontam na direção dos paradigmas crítico e clínico, tal como desenvolvidos em seção anterior. Isso tem repercutido em desenhos alternativos de investigação, os quais tentam combinar produção de conhecimento e intervenção em realidades laborais específicas, especialmente em contextos 
alternativos às organizações capitalistas tradicionais (empresas). Adicionalmente, o eixo clínico estimula uma ampliação no significado tradicional de clínica (centrada no indivíduo), passando a vê-la como um recurso para a compreensão e transformação de questões que perpassam o vínculo do sujeito com o trabalho.

\section{Eixos temáticos, dilemas e tensões}

Discutidos os paradigmas e os eixos da PTO, resta a análise de tensões que permeiam estes e influenciam os modos de se produzir conhecimento. Ela será feita por meio de um contínuo de relevância e rigor. Os eixos serão comparados entre si tomando seus distintos posicionamentos em relação aos dois polos deste contínuo.

\section{Relevância e rigor}

$\mathrm{Na}$ tentativa de assegurar a consistência do método experimental contra as críticas de diversos autores como Campbell e Stanley (1966), Orne (1962), Rosenthal (1966) propuseram o conceito de validade interna e validade externa. Conforme este autores, às custas da elevação da primeira, a segunda pode ser restringida (e vice-versa). Em outros termos, o resguardo de um modelo forte de pesquisa, calcado em operacionalizações consistentes de variáveis e modelos bem delineados, pode ter, como contrapartida, um impacto negativo no poder da generalização. Mirando esse fato e tomando a psicologia social como contexto, Ring (1967) somou-se às discussões com uma crítica sobre a falta de relevância dos conhecimentos gerados por aquela disciplina à sua época, a qual ele atribuía à excessiva preocupação com delineamentos experimentais. O questionamento não ficou restrito à psicologia social, mas avançou por diversos campos das ciências sociais (Gouldner, 1970). Mais recentemente, idêntica reflexão é observada na área da administração (Sutton \& Saw, 1995).

Dentro do eixo do comportamento é possível observar outras reações a essas críticas. A primeira é a emergência dos modelos quasi-experimentais (Cook \& Campbell, 1979). No interior do campo, o deslocamento para este método configura uma clara adoção dos pressupostos do paradigma pós-positivista ou do neopositivismo (Johnson \& Casssel, 2001; Steffy \& Grimes, 1992). Ele é similar ao positivismo na medida em que também adere aos objetivos da explicação e predição, bem como enfatiza o teste de relações de hipóteses e proposições usando medidas formais e objetivas. Mas dele se diferencia na medida em que rejeita a pressuposição de que as leis e teorias do comportamento podem ser diretamente confirmadas - admitindo, ao invés, um processo dedutivo pelo qual teorias concorrentes são gradualmente falsificadas (Popper, 1972).

Outra reação, já sinalizada, é a opção pelos métodos correlacionais e pelos surveys (Vaus, 2002). Um dos diferenciais, neste caso, é a introdução de premissas sobre a multicausalidade dos fenômenos investigados e a preocupação com problemas práticos vivenciados pelas organizações em seus respectivos ambientes. Houve ainda a adesão mais recente aos métodos multiníveis, os quais, segundo Klein e Kozlowski (2000), permitem construir pontes entre níveis macro e micro no estudo de fenômenos organizacionais, elevando a sensibilidade do pesquisador para captação de influências contextuais (topdown) e, ao mesmo tempo, dos processos que emergem do cotidiano organizacional (bottom-up). Inclusive, neste último caso, técnicas qualitativas podem ser utilizadas (triangulação). A crescente utilização dos métodos multiníveis decorreu de desenvolvimentos tecnológicos em informática, o que simplificou sua aplicação e facilitou o acesso dos pesquisadores aos mesmos.

A questão-chave deste contínuo é o quanto o rigor deve preponderar sobre a relevância, ou a que ponto esta última deve ser o orientador principal da investigação (Anderson, Herriot, \& Hodgkinson, 2001). Evidentemente, nem sempre uma postura elimina a outra. Contudo, há uma tensão nesse ponto e ela está ligada ao tipo de inserção da PTO em seu campo de estudos: as organizações capitalistas. Historicamente, essa inserção ocorreu sob o comando do positivismo e do pós-positivismo. Uma luta implícita de afirmação permeou a área desde sua emergência como disciplina científica: afirmação da validade e legitimidade dos conhecimentos e das intervenções por ela produzidos. Zickar e Gibby (2007) mostram que essa luta, ao menos no contexto norte-americano, materializou-se pelo recurso à quantificação. Essa estratégia consistia em contrapor os conhecimentos e tecnologias gerados pela PTO àqueles gerados, por exemplo, por consultores organizacionais orientados pela prática.

Como consequência da imersão quantitativa da área, métodos de pesquisa qualitativamente orientados desempenharam um papel menos saliente em seu desenvolvimento. Zickar e Gibby (2007) comentam que, a despeito disso, no início do século vinte alguns profissionais da PTO expressavam hesitação e cautela em relação à aplicação cega de técnicas estatísticas, em desenho experimental, aos fenômenos organizacionais. Assim, podiam-se observar metodologias alternativas, como a etnometodologia. Contudo, os autores comentam que, na segunda parte do século vinte, o cenário parece novamente ter se voltado em favor das perspectivas quantitativas e experimentais.

Do lado dos paradigmas neopositivistas, mais especificamente no eixo do comportamento, tensões no processo de produção de conhecimento emergem do dilema entre relevância e rigor situação discutida, no interior desse eixo, por Anderson, Herriot \& Hodgkinson (2001). Estes últimos autores mencionam que, devido às pressões dos distintos públicos de interesse, acadêmicos da PTO têm novamente migrado para pesquisas experimentais nos EUA pela maior facilidade de acesso a informações e controle de variáveis, além de serem desenhos nos quais, em tese, se consegue nível máximo de rigor - necessário para a construção e divulgação de artigos científicos em journals com forte pressão para delineamentos robustos de pesquisa.

Em contrapartida, os praticantes (psicólogos profissionais, por exemplo), devido à pressão de clientes, gestores e demais atores organizacionais, podem muitas vezes apelar para soluções paliativas, ao estilo de modas e modismos. Essa discrepância só faz aumentar a cisão no interior do eixo de comportamento em PTO, onde, na tradição neopositivista que o influenciou, questões de rigor permanecem centrais. Para piorar, e mesmo considerando o notório avanço representado pelos métodos multiníveis, o pesquisador e profissional PTO inspirados nas tradições neopositivistas podem, segundo advertência 
de Spink (1996), perder a noção de que as organizações são fenômenos psicossociais nos quais intervêm dimensões políticas e problematizações intrínsecas aos fenômenos do trabalho e processos organizativos nas sociedades pós-industriais. Uma possível evidência disto é a recente discussão sobre a necessidade de o pesquisador PTO do eixo do comportamento trabalhar suas competências políticas.

Outra variante dessa tensão surge do lado dos paradigmas não positivistas no âmbito da PTO. Se, no caso anterior, o rigor não significa relevância, também é verdade que a quantificação parece estar mais próxima do modo de funcionamento de uma organização capitalista. Veja-se, por exemplo, as apropriações de que são alvo algumas ferramentas da área por gestores interessados em comprovar cientificamente suas decisões (muitas vezes já tomadas - cabendo apenas serem justificadas). Por essa razão, pensando estritamente no universo organizacional capitalista, a tensão das abordagens não positivistas emerge da necessidade de negociação com o poder instituído. Algumas, de ênfase mais crítica, assumem abertamente uma postura questionadora desse poder.

Ao entrarem no contexto organizacional com uma perspectiva emancipadora, embutida nesse viés crítico, aquelas abordagens têm se de confrontar com as regras do jogo e afirmarse diante delas. Ora, o fato de algumas delas serem aplicadas em contextos não capitalistas típicos (por exemplo, em associações, instituições ou organizações cujo poder decisório é flexível ou cooperativo) pode ser indício de um tipo de marginalização ou então de uma estratégia de ajuste aos jogos de força existentes no campo do trabalho institucionalizado (no campo do emprego). A não metabolização da linguagem quantitativa cria a necessidade de se construírem outras linguagens capazes de inteligibilidade em contextos organizacionais capitalistas. Na ausência dessa tentativa de comunicação, as abordagens não positivistas correm o risco de serem aí tomadas como versões soft de difícil conexão com o mainstream decisório.

\section{Considerações Finais}

Há pouco mais de duas décadas a metáfora do lobo mau foi utilizada para analisar a atuação do psicólogo organizacional no Brasil (Codo, 1984). Com o surgimento de novos paradigmas opondo-se ao neopositivismo, o cenário tornou-se mais diversificado. No campo da PTO, isso implicou na construção de novos eixos de estudo e em novas formas de luta por afirmação. Esses novos eixos insistem na necessidade da mudança de perspectiva em nome da priorização do pólo da relevância, do impacto do conhecimento - visto como prática social comprometida. Junto à diversificação temática ocorreu também a diversificação de espaços de inserção: o foco ampliou-se da empresa ou organização capitalista para outras instituições, muitas vezes com demandas bem distintas daquela. Os novos paradigmas estabelecem novas hierarquias de valores, no âmbito das quais conceitos como rigor, método e objetividade são redefinidos.

Não há dúvida de que tal diversidade é sinal da maturidade da PTO em nosso país, mas também fator de preocupação. Isso porque tal cenário coloca sobre o pesquisador e profissional em questão a contínua necessidade de confrontar suas atividades com os referenciais que legitimam sua atuação. Por esse motivo, a reflexão crítica sobre as bases epistemológicas, ontológicas e metodológicas que orientam e fundamentam seu trabalho surge como condição essencial de sua competência profissional. Porém, não é fácil escolher entre extremos, da base positivista à clínica. Esse desafio tem sido agravado, desde a metade do século vinte, com a crescente complexidade da sociedade. A psicologia e as outras ciências sociais ainda procuram a metodologia capaz de abrigar e abranger a totalidade de seu objeto.

Para encerrar, destacamos que a discussão aqui promovida sobre o pluralismo paradigmático pode ser observada em mudanças concretas nas normas científicas, como atestado pelas alterações recentemente introduzidas no Manual da American Psychological Association (The Working Group on JARS, 2008). Ao mesmo tempo, transformações nas formas de institucionalização do trabalho (Malvezzi, 1999) e nos novos padrões de exigência de compromisso social endereçados à PTO (Bastos, 2009) também demandam revisões nas normas científicas reguladoras do campo, obrigando os sistemas de avaliação a reconhecer distintos critérios de produção de conhecimento. Esses movimentos são sinais de crescente complexidade de nossa ciência.

\section{Referências}

Anderson, N., Herriot, P., \& Hodgkinson, G. P. (2001). The practitioner-researcher divides in industrial, work and organizational psychology. Journal of Occupational and Organizational Psychology, 74, 391-411.

Athayde, M., \& Brito, J. (2010). Ergologia e clínica do trabalho. In P. F. Bendassolli, \& L. A. Soboll (Orgs.), Clínicas do trabalho: novas perspectivas para a compreensão do trabalho na atualidade (pp. 258-282). São Paulo: Atlas.

Ayer, A. J. (1959). Logic positivism. New York: Free Press.

Bandura, A. (1977). Social learning theory. New York: General Learning Press.

Bandura, A., \& Mischel, W. (1965). Modification of self-imposed delay of reward through exposure to live and symbolic models. Journal of Personality and Social Psychology, 2, 698-705.

Barros, V. A. (2009). O trabalho na contemporaneidade: delimitações de um mundo de exclusão. In Conselho Regional de Psicologia de Minas Gerais (Org.), Subjetividade(s) e sociedade: contribuições da psicologia (pp. 143160). Belo Horizonte: CRP-MG.

Bartlett, F. (1932). Remembering. Cambridge: Cambridge University Press.

Bastos, A. V. B. (2009). O mundo das organizações e do trabalho: o que significa compromisso social para a psicologia? In M. R. de Souza, \& F. S. Lemos (Orgs.), Psicologia e compromisso social: unidade na diversidade (pp. 9-42). São Paulo: Escuta.

Bastos, A. V. B., \& Gondim, S. (2010). O psicólogo e seu trabalho no Brasil. Porto Alegre: Artmed.

Bastos, A. V. B., \& Martins, A. H. C. G. (1989). O que faz o psicólogo organizacional. Psicologia: Ciência e Profissão, 9(3), 10-18.

Bendassolli, P. F., \& Soboll, L. A. (2010). Clínicas do trabalho: novas perspectivas para compreensão do trabalho na atualidade. São Paulo: Atlas.

Benoist, J. (1995). Subjectivité. In D. Kambouchner (Org.), Notions de philosophie, II (pp. 501-562). Paris: Gallimard.

Borges-Andrade, J. E. (1990). Avaliação da profissão segundo os psicólogos da área organizacional. Psicologia: Ciência e Profissão, 10(1), 19-23.

Borges-Andrade, J. E., Abbad, G. S., \& Mourão, L. (2006). Treinamento, desenvolvimento e educação em organizações e trabalho: fundamentos para a gestão de pessoas. Porto Alegre: Artmed. 
Brito, J., Athayde, M., \& Alvarez, D. (2004). Labirintos do trabalho. Rio de Janeiro: DP\&A

Bruner, J., Goodnow, J. J., \& Austin, G. A. (1956). A study of thinking. New York: Wiley.

Campbell, D., \& Stanley, J. (1966). Experimental and quasi-experimental designs for research. Chicago: Rand McNally and Company.

Carreteiro, T. C. O., \& Barros, V. A. (2010). Clínicas do trabalho: contribuições da psicossociologia no Brasil. In P. F. Bendassolli, \& L. A. Soboll (Orgs.), Clínicas do trabalho: novas perspectivas para a compreensão do trabalho na atualidade (pp. 208-226). São Paulo: Atlas.

Chanlat, J. F. (Org.). (1990). L'individu dans l'organisation. Montreal: Presses de 1'Université Laval.

Chapoulie, J.-M. (2001). La tradition sociologique de Chicago. Paris: Seuil.

Clot, Y. (2008). Travail et pouvoir d'agir. Paris: Presses Universitaires de France.

Codo, W. (1984). O papel do psicólogo na organização industrial: notas sobre o «lobo mau» em psicologia. In S. T. M. Lane, \& W. Codo (Orgs.), Psicologia social: o homem em movimento (pp. 195-202). São Paulo: Brasiliense.

Cook, T., \& Campbell, D. (1979). Quasi-Experimentation. Chicago: RandMcNally.

Davel, E., \& Vergara, S. C. (2001). Gestão com pessoas e subjetividade. São Paulo: Atlas.

Dejours, C. (1993). Travail, usure mental. Paris: Bayard.

Dejours, C. (1994). Psicodinâmica do trabalho. São Paulo: Atlas.

Dejours, C. (1999). Psychologie clinique du travail et tradition comprehensive. In Y. Clot (Org.), Les histories de la psychologie du travail (pp. 195-209). Toulouse: Octares.

Denzin, N. K. (1970). The research act. New Brunswick: Aldine Transaction.

Dilthey, W. (1992). Teorias das concepções do mundo. Lisboa: Edições 70 (Original publicado em 1911)

Echeverría, J. (1989). Introducción a la metodología de la ciencia. Barcelona: Barcanova.

Foucault, M. (1984a). L'archéologie du savoir. Paris: Gallimard.

Foucault, M. (1984b). L'usage des plaisirs. Paris: Gallimard.

Foucault, M. (1984c). Le souci de soi. Paris: Gallimard.

Foucault, M. (1986). Les mots et les choses. Paris: Gallimard.

Foucault, M. (1987). Surveiller et punir. Paris: Gallimard.

Freitas, M. E. (2005). Cultura organizacional: identidade, sedução e carisma? Rio de Janeiro: Editora da Fundação Getúlio Vargas.

Garfinkel, H. (1967). Studies in ethnometodology. Englewood Cliffs: PrenticeHall.

Gouldner, A. W. (1970). The coming crisis of western sociology. New York: Basic Books.

Guba, E. G. (1990). The paradigm dialog. Londres: Sage.

Hull, C. L. (1943). Principles of behavior. New York: Appleton-Century.

Johnson, P., \& Cassell, C. (2001). Epistemology and work psychology: new agendas. Journal of Occupational and Organizational Psychology, 74, $125-143$.

Klein, K. J, \& Kozlowski, S. W. J. (Orgs.).(2000). Multilevel theory, research, and methods in organizations. San Francisco: Jossey-Bass.

Kolakowski, A. W. (1972). Positivist philosophy from Hume to the Vienna Circle. Harmondsworth: Penguin.

Koppes, L. L., \& Pickren, W. (2007). Industrial and organizational psychology: an evolving science and practice. In L. L. Koppes (Org.), Historical perspectives in industrial and organizational psychology (pp. 3-36). New Jersey: Lawrence Erlbaum.

Kuhn, T. S. (1962). The structure of scientific revolutions. Chicago: Chicago University Press.

Lancman, S., \& Heloani, R. (2004). Psicodinâmica do trabalho : o método clínico de intervenção e investigação no trabalho. Revista Produção, 14(3), 77-86.
Lancman, S., \& Uchida, S. (2003). Trabalho e subjetividade : o olhar da psicodinâmica do trabalho. Cadernos de Psicologia Social do Trabalho, 6, 79-90.

Lhuilier, D. (2006). Cliniques du travail. Paris: Erès.

Macêdo, K. (1999). Psicodinâmica nas organizações: poder, cultura e decisão na empresa familiar. (Tese de doutorado, Pontifícia Universidade Católica de São Paulo, São Paulo).

Macêdo, K. (2010). O trabalho de quem faz arte e diverte os outros. Goiânia: Editora da Pontifícia Universidade Católica de Goiás.

Malvezzi, S. (1999). Psicologia Organizacional: da administração científica à globalização - uma história de desafios. In C. G. Machado, M. Melo, V. Franco, \& N. Santos (Orgs.), Interfaces da psicologia (pp. 313-326). Évora: Universidade de Évora.

Mannheim, K. (1936). Ideology and utopia. Orlando: Kessinger Publishing

Martuccelli, D. (2002). Grammaires de l'individu. Paris: Gallimard.

Mead, G. H. (1934). Mind, self and society. Chicago: Chicago University Press.

Mello, A. (2007). Trabalho e produção de subjetividade no mercado de capitais. (Dissertação de mestrado, Universidade Federal Fluminense, Niterói).

Mendes, A. M. (Org.).(2008). Trabalho e saúde: o sujeito entre emancipação e servidão. Curitiba: Juruá

Mendes, A. M., Merlo, A. R. C., Morrone, C. F., \& Facas, E. P. (2010). Psicodinâmica e clínica do trabalho. Curitiba: Juruá.

Menzies, I. (1970). The functioning of social systems as a defence against anxiety. Londres: Tavistock Institute.

Merlo, A. R. C. (2002). Psicodinâmica do trabalho. In M. G. Jacques, \& W. Codo (Orgs.), Saúde mental e trabalho: leituras (pp. 130-142). Petrópolis: Vozes.

Mettens, P. (2006). Psychanalyse et sciences cognitives: un même paradigme? Bruxelles: De Boeck.

Mezan, R. (2007). Que tipo de ciência é, afinal, a psicanálise? In J. FrayzePereira, \& M. Patto (Orgs.), Pensamento cruel (pp. 57-91). São Paulo: Casa do Psicólogo.

Miller, G. A., Galanter, E., \& Pribam, K. H. (1960). Plans and the structure of the behavior. New York: Holt, Rinehart and Wilson.

Montero, M. (1996). Paradigmas, corrientes y tendencias de la psicologia social finisecular. Psicologia \& Sociedade, 8(1), 102-119.

Nardi, H. C. (2006). Ética, trabalho e subjetividade. Porto Alegre: Editora da UFRGS.

Orne, M. T. (1962). On the social psychology of the psychological experiment. American Psychologist, 17, 776-783.

Osório da Silva, C., Barros de Barros, M. E., \& Louzada, A. P. F. (2010). Clínica da atividade: dos conceitos às apropriações no Brasil. In P. F. Bendassolli, \& L. A. Soboll (Orgs.), Clínicas do trabalho: novas perspectivas para compreensão do trabalho na atualidade (pp. 188-207). São Paulo: Atlas.

Pagés, M., Bonetti, M., Gaulejac, V. De, \& Descendre, D. (1986). L'emprise de l'organization. Paris: Presses Universitaires de France.

Popper, K. (1972). The poverty of historicism. New York: Harper.

Ramminger, T., \& Nardi, H. C. (2008). Subjetividade e trabalho: algumas contribuições conceituais de Michel Foucault. Interface: Comunicação, Saúde, Educação, 12(25), 339-346.

Ring, K. R. (1967). Experimental social psychology. Journal of Experimental Psychology, 3, 113-123.

Rorty, R. (1979). Philosophy and the mirror of nature. Princeton: Princeton University Press.

Rosenthal, R. (1966). Experimenter effects in the behavioral research. New York: Appleton Century Crofts.

Schutz, A. (1962). The problem of social reality. La Haya: Martinus Nijhoff.

Siqueira, M. M. M. (Org.).(2008). Medidas do comportamento organizacional. Porto Alegre: Artmed.

Spink, P. K. (1996). Organização como fenômeno psicossocial. Psicologia \& Sociedade, 8(1), 174-192. 
Steffy, B., \& Grimes, A. J. (1992). Personnel/Organizational psychology: a critique of the discipline. In M. Alvesson, \& H. Willmott (Orgs.), Critical management studies (pp. 181-201). London: Sage.

Sutton, R. I., \& Staw, B. M. (1995). What theory is not. Administrative Science Quarterly, 40, 371-384.

The Working Group on JARS (Journal Article Reporting Standards). (2008). Reporting Standards for Research in Psychology. American Psychologist, 63(9), 839-851

Tittoni, J., \& Nardi, H. C. (2006). Subjetividade e trabalho. In A. D. Cattani, \& L. Holzmann (Orgs.), Dicionário de trabalho e tecnologia (pp. 277-280). Porto Alegre: Editora da Universidade Federal do Rio Grande do Sul.

Vasconcelos, J., \& Davel, E. (2000). Recursos humanos e subjetividade. Petrópolis: Vozes.

Vaus, D. (2002). Surveys in social research. Londres: Routledege.

Vieira, A., \& Goulart, I. B. (Orgs.). (2007). Identidade e subjetividade na gestão de pessoas. Curitiba: Juruá.
Vygotski, L. S. (1991). Pensamento e linguagem. São Paulo: Martins Fontes. (Original publicado em 1934)

Weber, M. (2001). Ensayos sobre metodologia sociológica. Bueno Aires: Amorrortu. (Original publicado em 1922)

Weinberg, J. R. (1936). An examination of logical positivism. New York: Harcourt, Brace \& Company.

Zanelli, J. C. (2002). O psicólogo nas organizações de trabalho. Porto Alegre: Artmed.

Zanelli, J. C., \& Bastos, A. V. B. (2004). Inserção profissional do psicólogo em organizações e no trabalho. In J. C. Zanelli, A. V. B. Bastos, \& J. E. Borges-Andrade (Orgs.), Psicologia, organizações e trabalho no Brasil (pp. 466-491). Porto Alegre: Artmed.

Zickar, M. J., \& Gibby, R. E. (2007). Four persistent themes throughout the history of I-O psychology. In L. L. Koppes (Org.), Historical perspectives in industrial and organizational psychology (pp. 61-80). New Jersey: Lawrence Erlbaum.

Pedro F. Bendassolli, doutor em Psicologia Social pela Universidade de São Paulo, pós-doutor em Administração pela Université Paris 9, é professor adjunto na Universidade Federal do Rio Grande do Norte. Endereço para correspondência:

Rua Vicente Mesquita, 885, Apt ${ }^{\circ}$ 501, Lagoa Nova, Natal - RN, CEP: 59063-650. Telefone:

(84) 9968-8167. E-mail: pbendassolli@gmail.com

Jairo Eduardo Borges-Andrade, $\mathrm{PhD}$ em Sistemas Instrucionais pela Florida State University, pós-doutor pela Sheffield University, é professor titular na Universidade de Brasília. E-mail: jairo.borges@gmail.com Sigmar Malvezzi, PhD em Comportamento Organizacional pela Lancaster University, livre docente pela Universidade de São Paulo (2006), é professor associado na Universidade de São Paulo. E-mail: sigmar@ usp.br 